\title{
Development of manufacturing method of the MAP21 magnesium alloy prepared by selective laser melting (SLM)
}

\author{
KONRAD GRUBER $^{1,2}$, ADRIANNA MACKIEWICZ ${ }^{1 *}$, WOJCIECH STOPYRA ${ }^{1,2}$, \\ ROBERT DZIEDZIC ${ }^{1,2}$, TOMASZ KURZYNOWSKI ${ }^{1,2}$ \\ ${ }^{1}$ Centre for Advanced Manufacturing Technologies - Fraunhofer Project Center, \\ Wrocław University of Science and Technology, Wrocław, Poland. \\ ${ }^{2}$ Department of Laser Technologies, Automation and Production management, \\ Mechanical Engineering Faculty, Wrocław University of Science and Technology, Wrocław, Poland.
}

\begin{abstract}
Magnesium alloys are well known for their biocompatibility and biodegradable properties [9], [27] owing to the fact that magnesium is a mineral crucial for human body, especially for bone tissue. There are studies [17] on using WE43 additively manufactured magnesium scaffolds for full bone and soft tissue regeneration. Moreover, magnesium implants in bones were investigated as having higher bone-implant interface strength than titanium ones [3]. In this paper, the results of the studies on MAP21 magnesium powder selective laser melting process optimization as a starting point for further bioapplications are presented. MAP21 magnesium alloy owing to its high mechanical properties, excellent vibration damping characteristic and good creep resistance is a promising material to be tested for scaffold structures. The study for the first time shows successful SLM manufacturing of dense samples made of MAP21 alloy. Using an algorithm based on design of experiment (DoE) method [21], the SLM process parameters were designated. The porosity was investigated as a SLM process optimization parameter. High density of produced sample, up to $99 \%$, was achieved. Microstructure and oxidation level after selective laser melting (SLM) manufacturing were characterized. Fine grain microstructure and three kinds of precipitations were found $\mathrm{Nd}(\mathrm{Gd}, \mathrm{Zr}, \mathrm{Mg}), \mathrm{Mg}(\mathrm{Nd}, \mathrm{Gd}, \mathrm{Zr})$ and $\mathrm{Mg}(\mathrm{Zr}, \mathrm{Nd}, \mathrm{Gd}, \mathrm{Zn})$ ). In order to determine the mechanical properties of MAP21 alloy processed with SLM technology, static tensile tests and microhardness tests were conducted, resulting in mechanical properties $\left(R_{m}=167 \mathrm{MPa}, E=38.6 \mathrm{GPa}, 63-74 \mathrm{HB}\right)$ comparable with as-cast alloy. A discussion was held on further research opportunities for biomedical use of SLM-ed MAP21 alloy.
\end{abstract}

Key words: SLM, MAP21, Elektron 21, MAP21, microstructure, processing parameters

\section{Introduction}

In recent years, research on medicine in the field of cardiovascular, orthopedic, craniofacial and drug screening have been significantly developed by additive manufacturing (AM) [30]. Selective Laser Melting (SLM) is one of the AM technologies widely used for manufacturing of components from metal alloys powder. The technology enables us to form geometry which is impossible for conventional manufacturing methods to obtain [12]. Hence, SLM has been applied for the production of tissue regenerative bioactive scaffolds and porous implants [19], [26]. Studies show that scaffold structures build by additive manufacturing techniques allow for full regeneration of tissue. Furthermore, those structures can be totally biodegradable, depending on scaffold material [6], [26].

Medicine development focuses on common usage of biomaterials as bone substitutes, fixatives for fractured bones, ligament and tendon repair and total hip arthroplasty (THA). Materials for bone implants should be characterized by appropriate mechanical properties, same as bony tissue to be replaced, namely, high ten-

\footnotetext{
* Corresponding author: Adrianna Mackiewicz, ul. Królewska 9, 64-920 Piła, Poland. Phone: 0048512537 756, e-mail: adr.mackiewicz@gmail.com

Received: September 11th, 2019

Accepted for publication: November 28th, 2019
} 
sile strength, relatively low elastic modulus, low mass and proper surface porosity for strong implant-tissue interface [23]. Among currently used metallic biomaterials, such as stainless steel, titanium alloys and cobalt-chromium alloys, it has been researched that magnesium alloys are much more biocompatible and totally biodegradable [9], [27]. Magnesium alloys are the lightest metallic construction materials, what is crucial for implant application. Furthermore, biocorrosion products of magnesium alloys are not deleterious to the surrounding tissues. Previous research [3] shows that magnesium implants have higher boneimplant interface strength than titanium ones. It is critical to investigate new magnesium alloys which alloying elements are selected in consideration of their cytotoxicity and hemocompatibility [9]. Literature reports wide real and possible biomedical application of magnesium alloys, e.g., cardiovascular stents, bone screws, micro-clips for laryngeal microsurgery, biodegradable orthopedic implants and wound-closing devices [1]. However, magnesium is still used for unload-bearing implants. Nevertheless, there are attempts of improving manufacturing process of magnesium alloys, because of mechanical properties, because of its biomedical qualities. Material developed by alloy elements dissolution is limited by biocompatibility and biodegradation products toxicity [5].

Magnesium, as a very promising material for bioapplications, has the major disadvantages, though, which are high oxidation and low vaporization temperature (narrow temperature range between melting and boiling). It makes magnesium alloys processed by SLM challenging and an object of attempts to product dense samples for recent years. There are successful attempts in SLM manufacturing WE43 (Mg-Y-Nd-Zr) magnesium-based rare earth alloy [7]. MAP21 is a high strength magnesium-based rare earth alloy characterized by high creep and corrosion resistance and excellent vibration damping [17]. This study investigates the selective laser melting processing perspectives, as a start point for further researches focusing on bioapplications.

\section{Materials and methods}

\subsection{Design of experiment}

In order to find optimal SLM process parameters factors having major impact on results, should be designated. Literature reports that merely few of among over 130 parameters are crucial for SLM proc- ess, namely, layer thickness, laser power and scan velocity. These parameters can be combined with spot size into a linear energy density, which is a quotient of laser power deposited to the material per unit area per unit scan speed (Eq. (1)). The aforementioned parameters are general and do not allow for precise determination of energy, therefore, linear energy density can be treated as an optimization parameter [8], [15], [21], whereas scan velocity depends on time exposure $\left(t_{\text {expo }}\right)$ of laser on single point and pre-defined distance between these points (Eq. (2)).

$$
\begin{aligned}
& \rho_{1}=\frac{P}{D v_{\text {skan }}}\left[\mathrm{J} \cdot \mathrm{mm}^{-2}\right], \\
& v_{\text {scan }}=\frac{p_{\text {dist }}}{t_{\text {expo }}}\left[\mathrm{mm} \cdot \mathrm{s}^{-1}\right] .
\end{aligned}
$$

This study is based on design of experiment (DOE) approach to optimize the process and experiment algorithm presented in the research [21]. In order to reduce the amount of experiments, three factors have been chosen as variable for tree level full factorial $3^{\mathrm{K}}$ design. Main parameters have been fixed, based on previous experience with SLM magnesium processing: layer thickness of $0.05 \mathrm{~mm}$, laser spot size $(D=0.2 \mathrm{~mm})$ and distance between points $\left(p_{\text {dist }}=20 \mu \mathrm{m}\right)$. Four levels have been adopted for each of variable parameters and listed in Table 1. Thus, it makes 64 experiments to be conducted. This study was divided into three stages. The scope of the first stage was fabrication of thin walls (spot size width) in rectangular shape to investigate melting quality for each of defined combination of parameters.

Table 1. Defined values of variable process parameters for the first stage of experiment

\begin{tabular}{|l|c|c|c|c|}
\hline \multirow{2}{*}{\multicolumn{1}{|c|}{ Factors }} & \multicolumn{4}{c|}{ Levels } \\
\cline { 2 - 5 } & 1 & 2 & 3 & 4 \\
\hline Laser power, $P[\mathrm{~W}]$ & 65 & 70 & 75 & 80 \\
\hline Time exposure, $t[\mu \mathrm{s}]$ & 100 & 120 & 140 & 160 \\
\hline$F_{d}[\mathrm{~mm} / 100]$ & 1900 & 2000 & 2100 & 2200 \\
\hline
\end{tabular}

Process parameters combination have been accepted for the next stage, based on the first stage of study. The condition of approval of process parameters for further examinations are the similar width of wall to the laser spot size and complete wall penetration. The scope of the second stage was to investigate influence of scanning strategy and scanning line distance for density of cube samples. The stripes XY and alternate $X Y$ strategies have been investigated. In the alternate $\mathrm{XY}$ strategy, the surface is scanned once 
along the $\mathrm{X}$-axis and on the next layer - along the $Y$-axis (Fig. 1a). In the stripes XY strategy, the scanned surface is divided into smaller sub-areas, which are performed in a specific order (Fig. 1b). Impact of scanning line distance was investigated on each of accepted parameters combination of the first stage of experiment (Table 2).

Table 2. Defined values of variable process parameters for the second stage of experiment

\begin{tabular}{|l|c|c|c|c|}
\hline \multirow{2}{*}{ Factor } & \multicolumn{4}{|c|}{ Levels } \\
\cline { 2 - 5 } & 1 & 2 & 3 & 4 \\
\hline $\begin{array}{l}\text { Scanning line distance, } \\
l_{\text {dist }}[\mathrm{mm}]\end{array}$ & 0.06 & 0.08 & 0.10 & 0.12 \\
\hline
\end{tabular}

a)

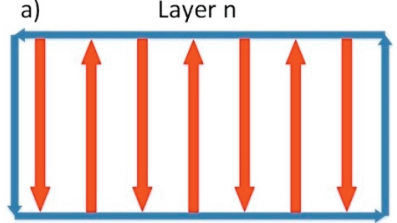

Layer $n+1$

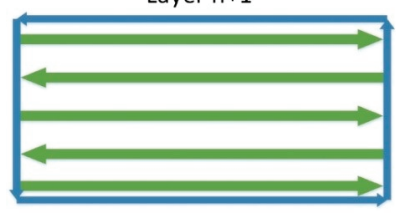

Fig. 1. Scanning strategies a) alternate $\mathrm{XY}$; b) stripes $\mathrm{XY}$

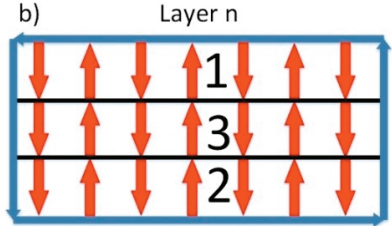

Layer $n+1$

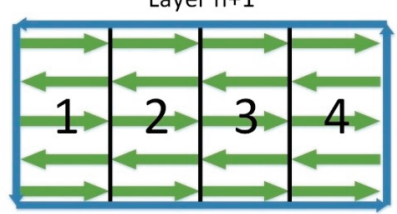

There were four levels of scanning line distance defined, hence, it was necessary to conduct 48 experiments. The porosity has been investigated on the crosssections of produced samples and examined using optical confocal microscopy. Porosity was an optimization parameter to designated superior process parameters combination.

The scope of the third stage of study was to conduct central rotatable design. The central point coordinates were based on superior parameters obtained from the previous stage. In this study, central rotatable design was used to analyze the influence of time exposition and laser power on porosity (Table 3 ). Rotatable design consists of two-level full design, star points and central point experiments. The design is characterized by symmetry on defined distance from the central point, what ensures constant estimation accuracy and number of experiments is more optimized than tree level full factorial $3^{\mathrm{K}}$ design.

Total number of experiments $(N)$ of rotatable design is defined by a dependence of number of analyzed variables $(K)$, number of experiments in a two level full factorial design $\left(2^{\mathrm{K}}\right)$, number of star points $(2 K)$ and number of center points $\left(N_{0}\right)$ (Eq. (3)). In this study, it was necessary to conduct 13 experiments.

$$
\begin{gathered}
N=2^{K}+2 K+N_{0}, \\
\frac{t \sqrt{2}}{t-\sqrt{2}}=t_{0} \pm \sqrt{2}\left(\frac{t_{+1}-t_{-1}}{2}\right) .
\end{gathered}
$$

In the two-level full design experiment, variables are changed at two levels \pm 1 . Respectively, the variables of star points experiment are changed at two levels $t \pm \sqrt{2}$ in line with Eq. (4). The aforementioned points of the experiments are located symmetrically to the main axes [21].

\subsection{Processing}

MAP21 powder used in this study has been supplied by Luxfer MEL Technologies corporation. Powder preparation contained screening and heating $\left(120{ }^{\circ} \mathrm{C} / 24 \mathrm{~h}\right)$ under pressure of $68 \mathrm{mbar}$ in order to vaporize water and removal of small particles. The majority of the particle size of powders was between 15 and $80 \mu \mathrm{m}$ and has regular spherical shape. Structure of powder particle surface was investigated by scanning electron microscopy (Fig. 2). SEM images shows oxide layer on the surface of the powder particles [16].

\begin{tabular}{|c|c|c|c|c|c|c|c|c|c|c|c|c|c|c|}
\hline & \multirow{2}{*}{ Factors } & \multicolumn{13}{|c|}{ Levels } \\
\hline & & 1 & 2 & 3 & 4 & 5 & 6 & 7 & 8 & 9 & 10 & 11 & 12 & 13 \\
\hline & $t_{1}$ & -1 & 1 & -1 & 1 & $-\sqrt{2}$ & $\sqrt{2}$ & 0 & 0 & 0 & 0 & 0 & 0 & 0 \\
\hline \multirow{3}{*}{ Test 5} & $t_{2}$ & -1 & -1 & 1 & 1 & 0 & 0 & $-\sqrt{2}$ & $\sqrt{2}$ & 0 & 0 & 0 & 0 & 0 \\
\hline & $t_{\text {expo }}[\mu \mathrm{s}]$ & 146 & 146 & 174 & 174 & 160 & 160 & 140 & 180 & 160 & 160 & 160 & 160 & 160 \\
\hline & $P[\mathrm{~W}]$ & 73 & 87 & 73 & 87 & 70 & 90 & 80 & 80 & 80 & 80 & 80 & 80 & 80 \\
\hline \multirow{3}{*}{ Test 4} & $t_{\text {expo }}[\mu \mathrm{s}]$ & 126 & 126 & 166 & 166 & 146 & 146 & 132 & 160 & 146 & 146 & 146 & 146 & 146 \\
\hline & $P[\mathrm{~W}]$ & 69 & 105 & 69 & 105 & 74 & 100 & 87 & 87 & 87 & 87 & 87 & 87 & 87 \\
\hline & & \multicolumn{4}{|c|}{ Two-level full design $2^{\mathrm{K}}$} & \multicolumn{4}{|c|}{ Star points } & \multicolumn{5}{|c|}{ Center point experiments } \\
\hline
\end{tabular}

Table 3. Values of build parameters at rotatable design variables 


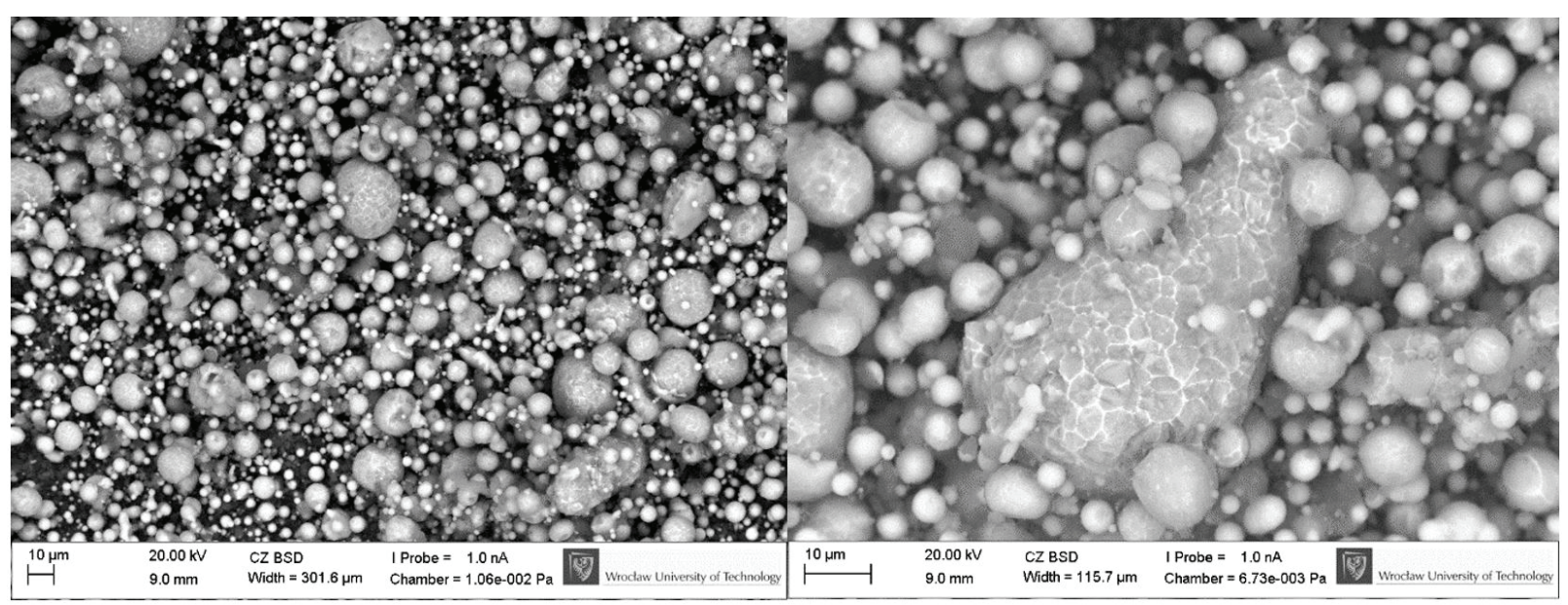

Fig. 2. SEM images of powder particles [16]

Chemical composition of supplied powder has been investigated by energy dispersive X-ray spectroscopy (EDS). The results (Table 4) shows slight deviations from the values declared by the manufacturer (values in brackets).

Table 4. Chemical composition of MAP21 alloy in wt. \%

\begin{tabular}{|c|c|c|c|c|}
\hline $\mathrm{Nd}$ & $\mathrm{Gd}$ & $\mathrm{Zn}$ & $\mathrm{Zr}$ & $\mathrm{Mg}$ \\
\hline 3.64 & 1.97 & 0.60 & Saturated & Balance \\
\hline$(2.60-3.10)$ & $(1.00-1.70)$ & $(0.20-0.50)$ & & \\
\hline
\end{tabular}

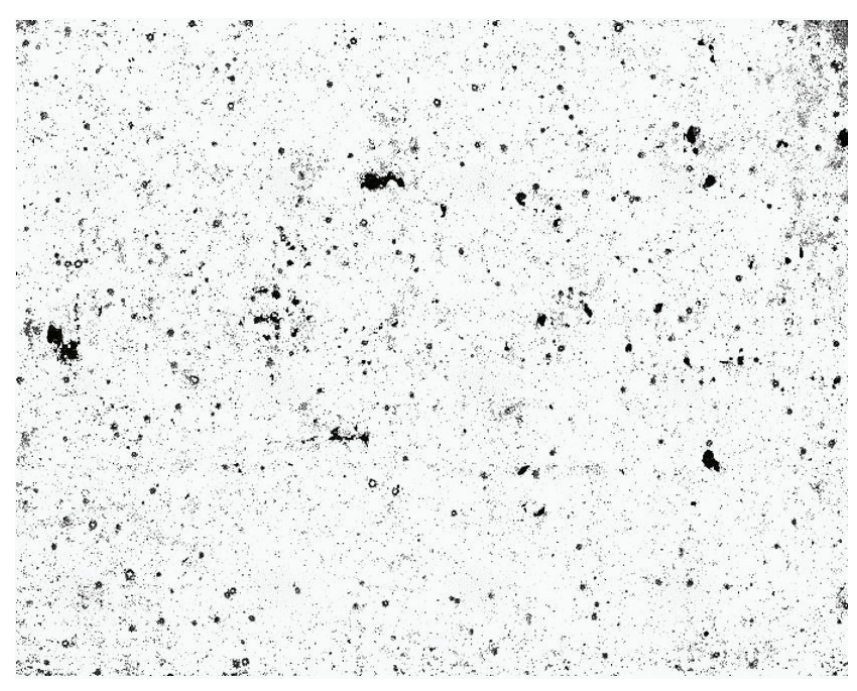

Fig. 3. Metallographic cross-section of MAP21 sample, specimen no. 2 of central rotatable design

SLM of MAP21 magnesium alloy powder was conducted using ReaLizer SLM250 apparatus with CW YLM Fiber Laser $(\lambda=1070 \mathrm{~nm})$ of power $20-400 \mathrm{~W}$. Samples were produced in a protective atmosphere of argon. Single track samples had dimensions of $7 \times 7 \mathrm{~mm}$ and $7 \mathrm{~mm}$ height and dense samples $-10 \times 8 \mathrm{~mm}$ and $6 \mathrm{~mm}$ height. Single tracks samples were photo- graphed and the track widths were measured by digital microscope. Metallographic cross-section specimens of dense samples were photographed using Olympus OLS4000 confocal microscope (Fig. 3) in order to conduct binarization and define specimen surface porosity.

Metallographic cross-sections of specimens were analyzed using Zeiss EVO MA25 SEM microscope. Microstructure was revealed after etching with $10 \%$ $\mathrm{HNO}_{3}$ solution in ethanol. In order to evaluate the quality of performed SLM process optimization, the comparative analysis was performed using cast alloy MAP21 properties [21].

Surface roughness of produced samples was measured according to PN-ISO 4288:1998 and PN-ISO 3274. Each of the values has been determined on a measuring section with a length of $l_{n}=40 \mathrm{~mm}$ and cutoff parameter of $\lambda_{C}=8 \mathrm{~mm}$. Measurements were performed using Olympus OLS4000 confocal microscope equipped with optical surface roughness measurements module. Roughness parameters were calculated using Olympus OLS4000 software.

Mechanical properties of as-built MAP21 specimens were investigated. Static tensile tests and microhardness Vickers tests were conducted. The static tensile strength tests were carried out using the INSTRON 3384 strength testing machine. A noncontact video-extensometer (AVE 2663-821) was used to measure elongation. Each sample was preloaded to $200 \mathrm{~N}$, then, the measurement was taken at the loading rate of $2 \mathrm{~mm} / \mathrm{min}$. The test finish criterion was the first loss of load as equivalent to the sample failure. Hardness measurement was performed on Zwick-Roel tester. In order to estimate process parameters optimization accuracy, comparison analysis was conducted in terms of properties declared by powder supplier. 


\section{Results}

\subsection{Porosity}

From the first stage (thin walls), the following parameters were selected: exposure time $160 \mu \mathrm{s}$, laser power $80 \mathrm{~W}, \mathrm{Fd} 2200 \mathrm{~mm} / 100$. As a result of the three-level full-factorial design (stage two) for three factors experiments, material porosity of $12.60 \%$ was obtained. Further experiments conducted in line with central rotatable design resulted in porosity of $1.04 \%$ (Fig. 3) with repeatability (SD $0.900 \%$ ) between 0.60 and $2.40 \%$ of porosity (Table 5 ). The least density has been obtained for alternate XY scan strategy and the following parameters: $t_{\text {expo }}=146 \mu \mathrm{s}, P=87 \mathrm{~W}$, $F_{d}=2200 \mathrm{~mm} / 100$ and $l_{\text {dist }}=0.10 \mathrm{~mm}$.

Four experiments for aforementioned parameters were conducted in order to determine estimation accuracy (Table 5).

Table 5. Porosity measurements of SLM processed MAP21 specimens

\begin{tabular}{|c|c|c|c|c|c|}
\hline Sample & $\begin{array}{c}\text { Density } \\
{[\%]}\end{array}$ & $\bar{x}[\%]$ & $s$ & $\bar{x}-t_{\alpha} \frac{s}{\sqrt{n-1}}$ & $\bar{x}-t_{\alpha} \frac{s}{\sqrt{n-1}}$ \\
\hline 1 & 99.40 & & & & \\
\cline { 1 - 2 } 2 & 97.60 & \multirow{2}{*}{98.34} & 0.900 & 96.690 & 99.997 \\
\cline { 1 - 2 } 3 & 98.78 & & & & \\
\hline 4 & 97.60 & & & & \\
\hline
\end{tabular}

\subsection{Microstructure}

MAP21 SLM processed alloy in as-built condition is characterized by fine-gained matrix with a size of 1-2 $\mu \mathrm{m}$ (Fig. 4b) and intermetallic phase precipitates at the grain boundaries (Fig. 4a, c, d).

The precipitates take the form of flakes with a size between 3 and $20 \mu \mathrm{m}$. The results of SEM analysis show the inhomogeneity of the chemical composition (Table 6) within the grain, the bright spots result from the greater presence of oxygen. The matrix (Fig. 4b) consists of $\mathrm{Mg}(\sim 85.9 \%$ at), and $\mathrm{Gd}(\sim 3.4 \%$ at $)$, $\mathrm{Nd}(\sim 3.1 \%$ at) and $\mathrm{Zr}(\sim 2.6 \%$ at). Oxidation level of the matrix is $5 \%$ at. The higher degree of oxygen affinity exhibits secretion at the level of $\sim 24.7 \%$ at and $\sim 15.9 \%$ at, whereas it increases along with the increase of $\mathrm{Mg}$ in the separation. Three types of precipitates have been observed: the first (Fig. 4c) based on $\mathrm{Mg}(\sim 29.4 \%$ at $), \mathrm{Nd}(\sim 16.6 \%$ at $), \mathrm{Gd}(\sim 9.0 \%$ at $)$ and $\mathrm{Zr}(\sim 8.1 \%$ at) and the other (Fig. $4 \mathrm{a})$ based on $\mathrm{Nd}$ $(\sim 38.0 \%$ at $), \mathrm{Gd}(\sim 22.4 \%$ at $), \mathrm{Zr}(\sim 10.8 \%$ at $)$ with a small amount of $\mathrm{Mg}(\sim 2.0 \%$ at). The third type of separation (Fig. 4d) occurs most frequently at the grain boundaries of the matrix and is the only fraction containing zinc. The composition resembles a strongly oxidized matrix: $\mathrm{Mg}(\sim 73.4 \%$ at $)$, and $\mathrm{Zr}(\sim 3.0 \%$ at $)$, $\mathrm{Nd}(\sim 1.6 \%$ at), Gd $(\sim 2.2 \%$ at) and $\mathrm{Zn}(\sim 2.5 \%$ at $)$.

The analysis of the elements distribution map enabled us to determine the residual oxide coatings of
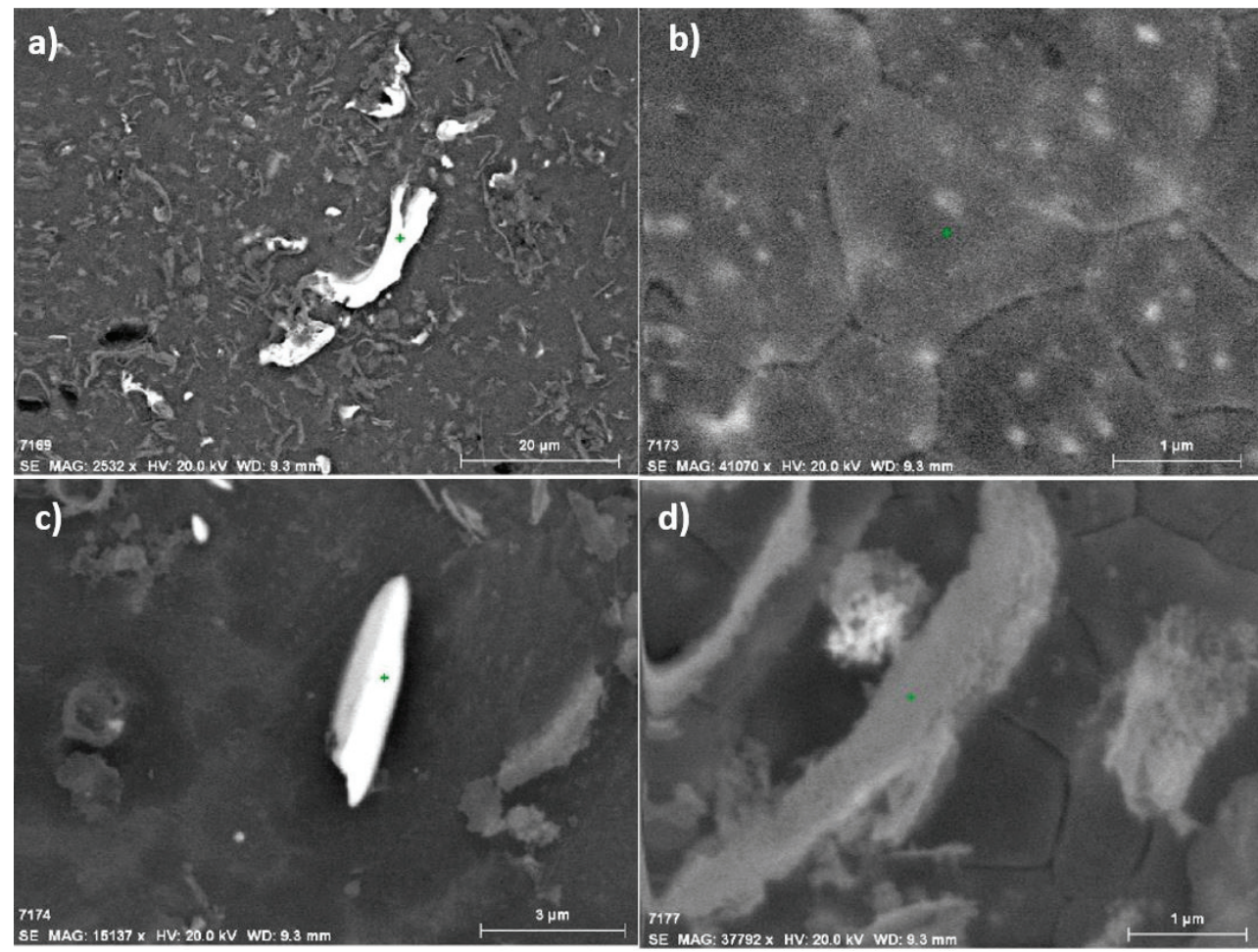

Fig. 4. SEM images of microstructure with indicated probe spot 
powder particles that have not dissolved in the liquid lake during the SLM process (Fig. 5). For confirmation, the size of the artifact was measured (Fig. 5), consistent with the range of the particle diameter of the powder particles. Oxidation occurred on the entire surface of the material. The white precipitates in the matrix are rare earth metal oxides (gadolinium and neodymium), without the presence of Mg. The matrix is composed of a solid solution phase $\alpha$ with interstitial $\mathrm{Mg}$ phase separations $(\mathrm{Nd}, \mathrm{Gd}, \mathrm{Zr}$ ). There is no visible share of zinc and zirconium on the maps. The presence of atypical elements results from the diffusion of atoms under the surface during the sputtering process of the EDS sample.

Table 6. Chemical composition of probe spots indicated in Fig. 4

\begin{tabular}{|c|c|c|c|c|c|c|}
\hline Probe spot & $\mathrm{Nd}$ & $\mathrm{Gd}$ & $\mathrm{Zn}$ & $\mathrm{Zr}$ & $\mathrm{Mg}$ & $\mathrm{O}$ \\
\hline 1 & 38.0 & 22.4 & - & 10.8 & 2.0 & 15.9 \\
\hline 2 & 3.2 & 3.4 & - & 2.6 & 85.9 & 5.0 \\
\hline 3 & 16.6 & 9.0 & - & 8.1 & 29.4 & 24.7 \\
\hline 4 & 1.6 & 2.2 & 2.5 & 3.0 & 73.4 & 26.0 \\
\hline
\end{tabular}
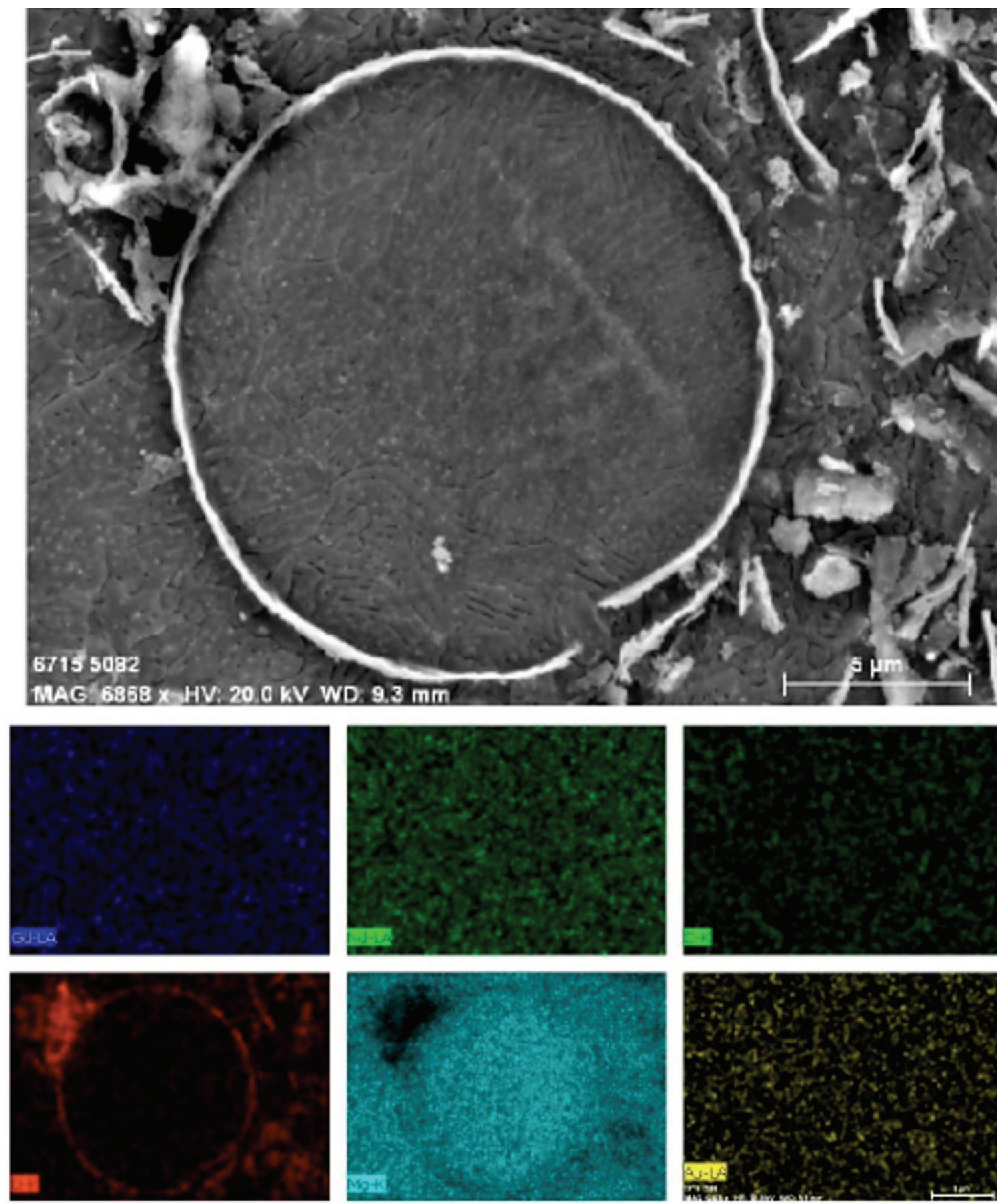

Fig. 5. SEM images of microstructure with element distribution maps 


\subsection{Surface roughness}

To validate surface quality after the SLM processing of MAP21, four surface roughness parameters were determined: $R_{a}, R_{z}, R_{q}$ and $R_{p}$. Each parameter was measured in two perpendicular directions: $x y$ plane

Table 7. Surface roughness of MAP21 specimens depending on the measurement plane

\begin{tabular}{|l|c|c|c|c|}
\hline \multicolumn{1}{|c|}{ Plane } & $R_{a}[\mu \mathrm{m}]$ & $R_{z}[\mu \mathrm{m}]$ & $R_{q}[\mu \mathrm{m}]$ & $R_{p}[\mu \mathrm{m}]$ \\
\hline $\begin{array}{l}x z \text { (parallel to } \\
\text { building direction) }\end{array}$ & 20.159 & 220.249 & 25.534 & 125.404 \\
\hline $\begin{array}{l}x y \text { (perpendicular to } \\
\text { building direction) }\end{array}$ & 22.307 & 232.474 & 28.177 & 140.322 \\
\hline
\end{tabular}

(sample plane parallel to the building direction) and $x y$ plane (sample plane perpendicular to the building direction). The measurement results are shown in Table 7.

Values of calculated surface parameters between different measurement planes do not show significant differences, not exceeding $10 \%$ of their values for each of the determined parameter. Attention should be paid to the high values of the $R_{z}$ parameter, which results from the uncapped powder particles present on the surface of the samples. Microscopic observation of samples surfaces shows largely developed surface, with a numerous non-melted particles (Fig. 6), which is the reason for the high values of the profiles maximum height parameter $R_{z}$. Top surface of the sample ( $x y$ plane) shows less non-melted powder particles than
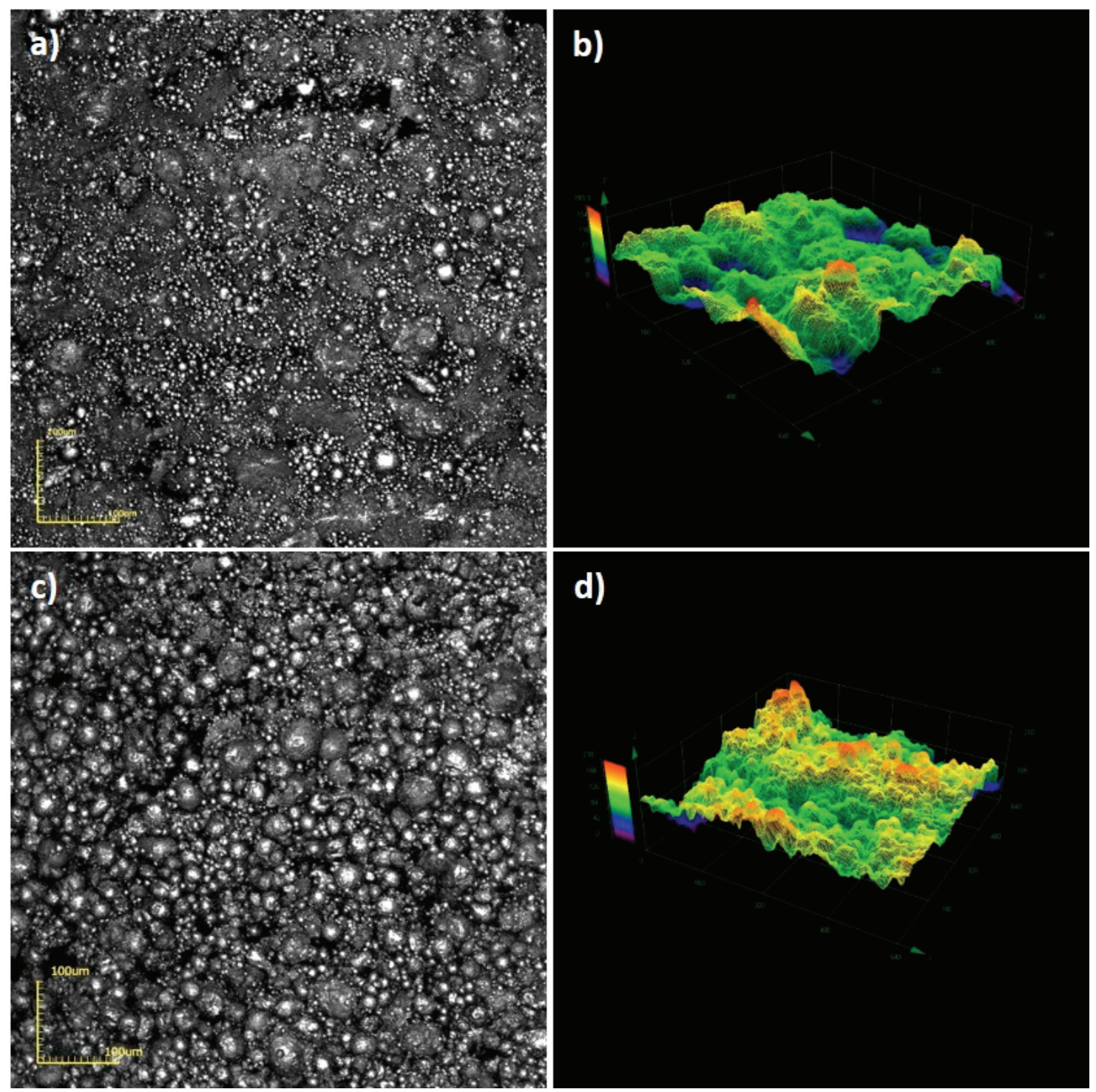

Fig. 6. Surface of as-built MAP21 specimens: a) $x y$ plane - top sufrace, b) 3D topology map of $x y$ plane, c) $x z$ plane - side surface, d) 3D topology map of $x z$ plane 
side surface ( $x z$ plane), which is typical for SLM-produced specimens. Calculated $R a$ parameter is very similar to values described in the literature for SLM-ed magnesium alloys [20].

\subsection{Strength and microhardness tests}

In this study, four static tensile tests were conducted. Proposed specimens' geometry of tensile test based on ASTM D1708-10 and PN EN ISO 68921 (Fig. 7). Specimens orientation (loading direction) during SLM processing was horizontal to the building platform.

Tensile tests show ultimate strength of as-built MAP21 of $167 \mathrm{MPa}$. The exemplary graph (Fig. 8) have a shape characteristic for brittle materials, there is no visible yield point and the elongation at break is negligible $(A=0.5 \%)$. The results of the measurements are presented in Table 8. In the statistical calculations, the formulas for the standard deviation and the confidence interval for the Student's $t$ distribution were used. For the significance level $\alpha=0.05$, it was

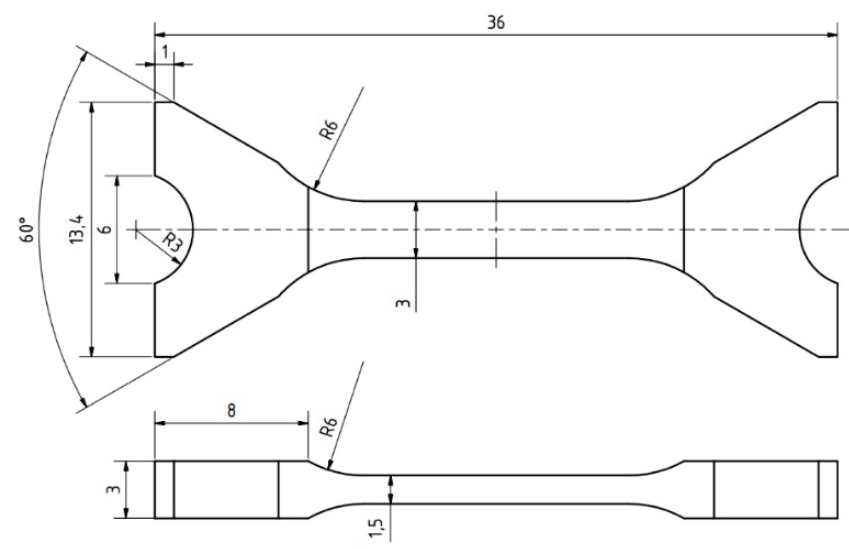

Fig. 7. Specimen geometry for static tensile test calculated that the obtained results are within the assumed range (Table 8).

\section{Discussion}

In this study, microstructure and mechanical properties of MAP 21 alloy processed by SLM have been shown. Microstructure of SLM as-built condition is much finer than as-cast condition presented in the study [14] (Fig. 9). Grain size of as-cast condition is between 20 and $30 \mu \mathrm{m}$, whereas grain size of as-built SLM condition is $1-2 \mu \mathrm{m}$. As-built SLM condition is characterized by fine dendritic microstructure with a large number of precipitates of 5-20 $\mu \mathrm{m}$ in size. The difference in the grain size of the microstructures results from the rapid solidification of the liquid metal pool in the SLM process. Both of states consist of intermetallic $\alpha$ phase with precipitates on grain boundaries. There are the difference in precipitates composition, wherein there have been observed three kinds of precipitates in as-built condition, each of them were oxidized varying degrees. Higher oxidation results from

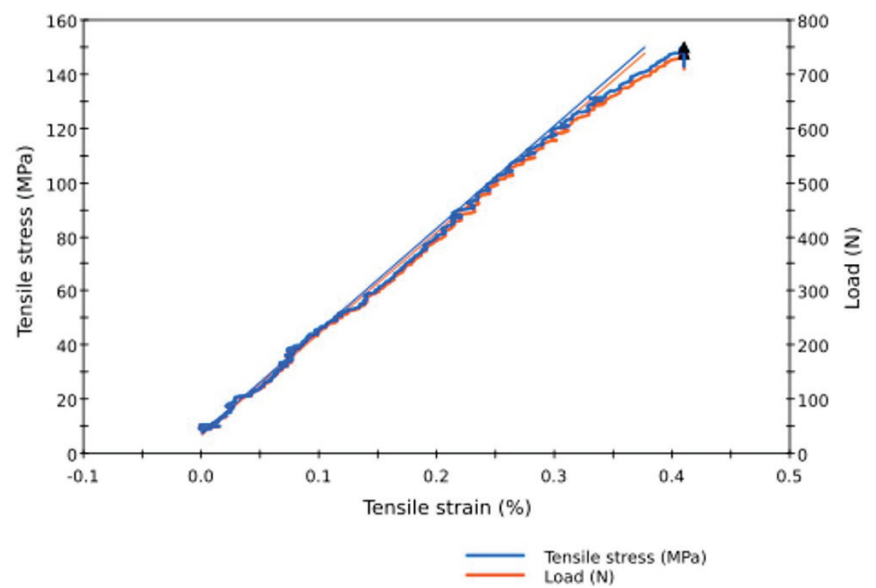

Fig. 8. Static stress-strain curves of as-built MAP21 specimens

Table 8. Results of static tensile test of as-built MAP21 specimens

\begin{tabular}{|c|c|c|c|c|}
\hline Sample & $R_{m}[\mathrm{MPa}]$ & $R_{e 0.2}[\mathrm{MPa}]$ & $E[\mathrm{GPa}]$ & $A[\%]$ \\
\hline 1 & 147.38 & 103.68 & 31.60 & 0.51 \\
\hline 2 & 181.52 & 114.08 & 40.51 & 0.47 \\
\hline 3 & 150.05 & 85.23 & 41.74 & 0.41 \\
\hline 4 & 188.28 & 150.75 & 40.63 & 0.62 \\
\hline $\bar{x}$ & 166.81 & 113.43 & 38.62 & 0.50 \\
\hline$s$ & 18.28 & 23.89 & 4.08 & 0.07 \\
\hline $\bar{x}-t_{\alpha} \frac{s}{\sqrt{n-1}}$ & 128.04 & 69.53 & 31.12 & 0.36 \\
\hline $\bar{x}+t_{\alpha} \frac{s}{\sqrt{n-1}}$ & 205.58 & 157.33 & 46.12 & 0.64 \\
\hline
\end{tabular}


a strong oxidation tendency of magnesium and a large number of oxides on the surface of powder particles [10], [24].

In this study, mechanical properties of as-built SLM condition have been compared to the ones declared by powder manufacturer for as-cast conditions of the same alloy (Table 9). The samples obtained in the study have lower strength properties $\left(R_{m}=167 \mathrm{MPa}\right.$, $E=38.6 \mathrm{GPa})$ than as-cast condition properties $\left(R_{m}=248 \mathrm{MPa}, E=44.8 \mathrm{GPa}\right)$. Hardness of the same value has been obtained though. It is supposed that the high oxidation state of intermetallic precipitants and oxide layer residues from the powder particles have an impact on the drop of plasticity and strength of asbuilt SLM samples.

Table 9. Comparison of mechanical properties resulted from SLM processed samples with as-cast condition and cortical bone

\begin{tabular}{|l|c|c|c|}
\hline & $\begin{array}{c}\text { As-cast } \\
\text { condition }\end{array}$ & $\begin{array}{c}\text { As-built } \\
\text { SLM } \\
\text { condition }\end{array}$ & $\begin{array}{c}\text { Cortical bone } \\
\text { (natural) } \\
{[20],[28]}\end{array}$ \\
\hline $\begin{array}{l}\text { Elastic modulus, } \\
E[\mathrm{GPa}]\end{array}$ & 44.8 & 38.6 & $7.0-30.0$ \\
\hline $\begin{array}{l}\text { Brinell hardness } \\
\text { [HB] }\end{array}$ & $65-75$ & $63-74$ & - \\
\hline $\begin{array}{l}\text { Apparent elastic limit } \\
0.2 \%[\mathrm{MPa}]\end{array}$ & 145 & 113 & - \\
\hline $\begin{array}{l}\text { Ultimate strength, } \\
R_{m}[\mathrm{MPa}]\end{array}$ & 248 & 167 & $107-146$ \\
\hline Tensile strain [\%] & 2.0 & 0.5 & $1.7-3.8$ \\
\hline
\end{tabular}

In Table 9 [23], a comparison of strength properties of MAP21 samples made using the SLM technology and the properties of human bones is presented. The obtained properties of the MAP21 alloy are similar to those of human bones, but slightly outweigh them. However, a smaller elongation has been noted. Appropriate preparation and storage of magnesium powder, together with reduced oxygen content during the SLM process, may reduce the amount of heterogeneous inclusions formed in the form of oxides, which may result in a decrease in the strength properties of the processed material and improve its elongation. Such powder preparation can further bring the strength properties of MAP21 alloy closer to those characterizing human bones. In addition, the stiffness of specific endoprostheses can be modified by changing the geometry, e.g., designed porosity or scaffold-type structures [22].

Measured surface quality of produced samples can be qualified as satisfactory within SLM technology standard, as it can be found in the literature, that typical calculated Ra parameter for SLM-ed Mg alloys as-build surfaces are within $20-30 \mu \mathrm{m}$ [25] or even $50 \mu \mathrm{m}$ [11] in some cases. Nevertheless, this type of surface is not sufficient for direct implant usage. Literature reports, that especially for usage in scaffold structures, SLM-ed surface needs to be modified to meet both fatigue loads [29] and cell adhesion requirements [3].

Based on the obtained results, it can be assumed that the use of the MAP21 alloy produced via SLM process has a potential of becoming a good material for biomedical applications. Further evolution of the microstructure and mechanical properties of the alloy is necessary. Therefore, also other factors should be considered, such as:

- biocompatibility - literature has shown, that alloying elements of MAP21 such as $\mathrm{Zr}, \mathrm{Zn}$ and Nd added to the $\mathrm{Mg}$ alloys matrix can be absorbed by surrounding tissue and are biological nutrients or non-toxic elements [18]. In the case of last MAP21 alloying element, gadolinium, there are no enough

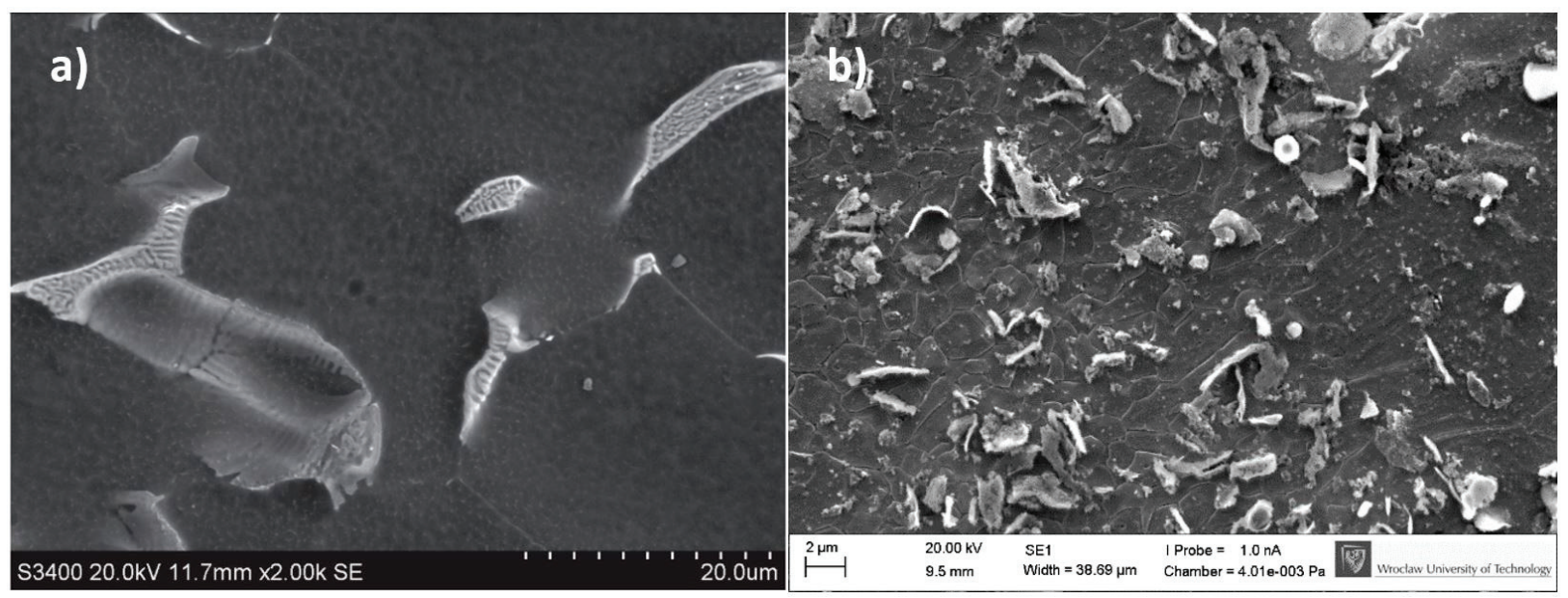

Fig. 9. Comparison of MAP 21 microstructure in: a) as-cast condition [14], b) as-built condition after SLM process 
research data to form final conclusions, but recent in vivo and in vitro studies on Gd-containing $\mathrm{Mg}$ alloys, qualified $\mathrm{Gd}$ as a promising addition to $\mathrm{Mg}$ alloy in case of biocompatibility, corrosion resistance and strength enhancing abilities [13];

- cytotoxicity - in vitro and in vivo studies must be planned and performed. Recent studies on similar SLM-ed Mg alloy, WE43, revealed similar cytotoxicity, compared to SLM-ed $\mathrm{Ti}_{6} \mathrm{Al}_{4} \mathrm{~V}$, after $24 \mathrm{~h}$, with level 0 cytotoxicity at $75 \%$ of the investigated time points and indistinguishable cytotoxicity after $48 \mathrm{~h}$ at $100 \%$ of time points [17];

- surface modification - surface of magnesium implants can be improved in various ways. Depending on the effect to be achieved (e.g., improving cell adhesion, improving corrosion properties), different types of treatments can be used, for example: acid baths, sandblasting, surface alloying or conversion coatings [2], [4]. Further investigation of SLM-ed MAP21 alloy properties, will enable us to choose appropriate surface modification procedures;

- powder preparation - due to the high propensity of magnesium alloys to react with oxygen and hydrogen, it is important to ensure proper preparation, storage and reuse of powders in SLM technology. The development of rigorous procedures can significantly reduce the oxidation of powder surfaces and the formation of strengthening, high-melting oxygen-containing inclusions;

- SLM process improvements - modification of the device structure to implement a laminar shielding gas flow will improve the removal of melting products (evaporating material, spatters) and thus reduce process disturbances as well as uniformity of the obtained microstructure in the entire working volume of the device; increasing the thickness of the layer to reduce the oxidation degree of the samples, however, while increasing the surface roughness [25];

- corrosion resistance $-\mathrm{Mg}$ alloys with the addition of rare earth elements, show increased corrosion resistance to other magnesium alloys. It is no different in the case of $\mathrm{Mg}$ alloys with the addition of gadolinium. Kania et al. [13] investigated electrochemical corrosion resistance in Ringer's solution at $37{ }^{\circ} \mathrm{C}$ of $\mathrm{MgCa}_{5-x} \mathrm{Zn}_{1} \mathrm{Gd}_{x}$ alloys, were the best results were achieved for $2 \mathrm{wt} . \%$ Gd addition. Therefore, corrosion studies of MAP21, containing up to $2 \mathrm{wt}$. \% of Gd, should be a further interest.

\section{Conclusion}

The research algorithm allowed to determine SLM process parameters effectively and efficiently. The results are characterized by repeatability and the determined porosity is in the range of $0.6-2.4 \%$. The maximum porosity of melted material should be not higher than $1.0 \%$, hence further parameters optimization or hot isostatic pressing (HIP) should be carried out in order to minimalize porosity. Nevertheless, porosity may be useful in medical applications to facilitate tissue adhesions.

SLM manufactured MAP21 alloy microstructure is much finer than conventionally manufactured material. There was no column texture observed. There are three kinds of precipitations determined: $\mathrm{Nd}(\mathrm{Gd}, \mathrm{Zr}$, $\mathrm{Mg}$ ), $\mathrm{Mg}(\mathrm{Nd}, \mathrm{Gd}, \mathrm{Zr})$ and $\mathrm{Mg}$ (Zr, Nd, Gd, Zn). Oxidation state rises along with the content of RE elements ad magnesium in a lesser degree. Thus rare earth elements precipitations have greater affinity to oxygen than groundmass.

Mechanical properties of SLM manufactured samples in the raw state $\left(R_{m}=167 \mathrm{MPa}, R_{p 0,2}=113 \mathrm{MPa}\right.$, $E=39 \mathrm{GPa}, A=0.5 \%$ ) are lower than properties of material manufactured conventionally, the microhardness $(63-74 \mathrm{HB})$ is on the same level though. Thus, it is necessary to conduct a heat treatment (supersaturation and aging) to achieve superior mechanical properties. The reduction in plasticity may result from the increased oxygen content, up to $26 \mathrm{wt}$. \% in precipitations. The material oxidation results in residual stresses which leads to further microcracking and deformations. Oxygen is delivered into melted material, inter alia, by oxidized surface of the powder particles. Therefore, the smaller particles are the higher oxidation level is, which is caused by increasing the powders active area.

Further studies are planned to focus on optimization of the SLM process to improve material quality and tissue-implant interface strength of SLM manufactured MAP21 alloy. Further aspects are also planned to be further investigated, such as in vivo and in vitro tests, corrosion resistance studies and surface modification trials.

\section{Acknowledgements}

The researches have been conducted as part of the project: "Magnesium-based alloys processed by selective laser melting for aerospace applications" (LIDER/8/0109/L-7/15/NCBR/2016) carried out in the CAMT Laboratory of Mechanical Department of Wrocław University of Science and Technology. 


\section{References}

[1] Ali M., Hussein M.A., Al-Aqeeli N., Magnesium-based composites and alloys for medical applications: A review of mechanical and corrosion properties, J. Alloys Compd., 2019, 792, 1162-1190, DOI: 10.1016/ j.jallcom.2019.04.080.

[2] Bartolo P., Kruth J.-P., Silva J., Levy G., Malshe A., Rajurkar K., Mitsuishi M., Ciurana J., Leu M., Biomedical production of implants by additive electro-chemical and physical processes, CIRP Ann., 2019, 61(2), 635-655, DOI: 10.1016/j.cirp.2012.05.005.

[3] Castellani C., Lindtner R.A., Hausbrandt P., TschegG E., StANZL-TscheGg S.E., ZANONi G., Beck S., WeinBerg A.-M., Bone-implant interface strength and osseointegration: Biodegradable magnesium alloy versus standard titanium control, Acta Biomater., 2011, 7(1), 432-440, DOI: 10.1016/ j.actbio.2010.08.020.

[4] Chakraborty B.P., Al-SaAdi S., Choudhary L., Harandi S.E., Singh R., Magnesium Implants: Prospects and Challenges, Materials, 2019, 12(1), 136, DOI: 10.3390/ ma12010136.

[5] Chen J., TAN L., Yu X., Etim I.P., Ibrahim M., YanG K., Mechanical properties of magnesium alloys for medical application: A review, J. Mech. Behav. Biomed. Mater., 2018, 87, 68-79, DOI: 10.1016/j.jmbbm.2018.07.022.

[6] Chen Y., Xu Z., Smith C., SAnkar J., Recent advances on the development of magnesium alloys for biodegradable implants, Acta Biomater., 2014, 10(11), 4561-4573, DOI: 10.1016/ j.actbio.2014.07.005.

[7] Gangireddy S., Gwalani B., Liu K., Faierson E.J., MisHRA R.S., Microstructure and mechanical behavior of an additive manufactured (AM) WE43-Mg alloy, Addit. Manuf., 2019, 26, 53-64, DOI: 10.1016/ j.addma.2018.12.015.

[8] GeBHARDT A., Understanding additive manufacturing: rapid prototyping, rapid tooling, rapid manufacturing, Hanser Publishers, Munich, Cincinnati, 2012, DOI: 10.3139/ 9783446431621.

[9] Gu X., Zheng Y., Cheng Y., Zhong S., XI T., In vitro corrosion and biocompatibility of binary magnesium alloys, Biomaterials, 2009, 30(4), 484-498, DOI: 10.1016/ j.biomaterials.2008.10.021.

[10] Gulbransen E.A., The oxidation and evaporation of magnesium at temperatures from $400{ }^{\circ} \mathrm{C}$ to $500^{\circ} \mathrm{C}$, J. Electrochem. Soc., 1945 (87), 589-599, DOI: 10.1149/1.3071667.

[11] Hu D., Wang Y., Zhang D., Hao L., Jiang J., Li Z., CHEN Y., Experimental Investigation on Selective Laser Melting of Bulk Net-Shape Pure Magnesium, Mater. Manuf. Process, 2015, 30(11), 1298-1304, DOI: 10.1080/ 10426914.2015.1025963.

[12] Junka A.F., Szymczyk P.E., Secewicz A., Pawlak A., SMUTNiCKA D., ZióŁKowski G.J., BARTOSZEWICZ M., CHLEBUS E., The chemical digestion of Ti6Al7Nb scaffolds produced by Selective Laser Melting reduces significantly ability of Pseudomonas aeruginosa to form biofilm, Acta Bioeng. Biomech., 2016, 012016, ISSN 1509-409X, DOI: 10.5277/ABB-00333-2015-01.

[13] Kania A., Nowosielski R., Gawlas-Mucha A., Babilas R., Mechanical and Corrosion Properties of Mg-Based Alloys with Gd Addition, Materials, 2019, 12(11), 1775, DOI: 10.3390/ ma12111775.
[14] KieŁbus A., Microstructure and mechanical properties of Elektron 21 alloy after heat treatment, J. Achiev. Mater. Manuf. Eng., 2007, 20, 4.

[15] Kurzynowski T., Chlebus E., Kuźnicka B., Reiner J., Parameters in selective laser melting for processing metallic powders, [in:] E. Beyer, T. Morris (Eds.), San Francisco, California, USA, 2012, 823914, DOI: 10.1117/ 12.907292 .

[16] Kurzynowski T., Szymczyk P.E., ZióŁKowski G.J., Dziedzic R., Pawlak A.P., Gruber K., Annual report on the implementation of the AMgAvio project for 2017, Magnesium based alloys processed by selective laser melting for aerospace applications, Mechanical Department of Wrocław University of Science and Technology, Wrocław 2018.

[17] Li Y., Zhou J., Pavanram P., Leeflang M.A., Fockaert L.I., POURAN B., TÜMER N., SCHRÖDER K.-U., MOL J.M.C., WeInANS H., JAHR H., ZADPOOR A.A., Additively manufactured biodegradable porous magnesium, Acta Biomater., 2018, 67, 378-392, DOI: 10.1016/j.actbio.2017.12.008.

[18] Liu C., Ren Z., Xu Y., Pang S., ZhaO X., Zhao Y., Biodegradable Magnesium Alloys Developed as Bone Repair Materials: A Review, Scanning, 2018, 1-15, DOI: 10.1155/ 2018/9216314.

[19] LiU C., ZhANG M., CHEN C., Effect of laser processing parameters on porosity, microstructure and mechanical properties of porous $\mathrm{Mg}-\mathrm{Ca}$ alloys produced by laser additive manufacturing, Mater. Sci. Eng. A., 2017, 703, 359-371, DOI: 10.1016/j.msea.2017.07.031.

[20] ManaKari V., Parande G., GuPTA M., Selective Laser Melting of Magnesium and Magnesium Alloy Powders: A Review, Metals, 2016, 7(1), 2, DOI: 10.3390/met7010002.

[21] Pawlak A., Rosienkiewicz M., Chlebus E., Design of experiments approach in AZ31 powder selective laser melting process optimization, Arch. Civ. Mech. Eng. 2017, 17 (1), 9-18, DOI: 10.1016/j.acme.2016.07.007.

[22] Roy S., DAS M., Chakraborty P., Biswas J.K., Chatterjee S., Khutia N., Saha S., Chowdhury A.R., Optimal selection of dental implant for different bone conditions based on the mechanical response, Acta Bioeng. Biomech., 2017, 19 (2), DOI: 10.5277/ABB-00530$-2015-03$.

[23] Ryniewicz A.M., Bojko Ł., Ryniewicz W.I., Microstructural and micromechanical tests of titanium biomaterials intended for prosthetic reconstructions, Acta Bioeng. Biomech., 2016, DOI: 10.5277/ABB-00193-2014-02.

[24] Salehi M., Maleksaeedi S., Farnoush H., Nai M.L.S., MeEnashisundaram G.K., Gupta M., An investigation into interaction between magnesium powder and Ar gas: Implications for selective laser melting of magnesium, Powder Technol., 2018, 333, 252-261, DOI: 10.1016/j.powtec.2018.04.026.

[25] Savalani M.M., Pizarro J.M., Effect of preheat and layer thickness on selective laser melting (SLM) of magnesium, Rapid Prototyp J., 2016, 22(1), 115-122, DOI: 10.1108/ RPJ-07-2013-0076.

[26] Tovar N., Witek L., Atria P., Sobieraj M., Bowers M., Lopez C.D., Cronstein B.N., Coelho P.G., Form and functional repair of long bone using 3D-printed bioactive scaffolds, J. Tissue Eng. Regen. Med., 2018, 12 (9), 1986-1999, DOI: $10.1002 /$ term.2733.

[27] Witte F., Kaese V., Haferkamp H., Switzer E., Meyer-Lindenberg A., WirTh C.J., WindHAGEN H., In vivo corrosion of four magnesium alloys and the associated bone re- 
sponse, Biomaterials, 2005, 26(17), 3557-3563, DOI: 10.1016/ j.biomaterials.2004.09.049.

[28] Yang Y., He C., Dianyu E., Yang W., Qi F., Xie D., Shen L., Peng S., Shuai C., Mg bone implant: Features, developments and perspectives, Mater., Des., 2020, 185, 108259, DOI: 10.1016/j.matdes.2019.108259.

[29] YuAn L., Ding S., Wen C., Additive manufacturing technology for porous metal implant applications and triple minimal surface structures: A review, Bioact. Mater., 2019, 4 (1), 56-70, DOI: 10.1016/j.bioactmat.2018. 12.003 .

[30] Zhao D., Witte F., Lu F., Wang J., Li J., Qin L., Current status on clinical applications of magnesium-based orthopaedic implants: A review from clinical translational perspective, Biomaterials, 2017, 112, 287-302, DOI: 10.1016/ j.biomaterials.2016.10.017. 